\title{
BARREIRAS A INOVAÇÃO EM NEGÓCIOS CIRCULARES QUE COMBATEM A PERDA E O DESPERDÍCIO DE ALIMENTOS NO BRASIL
}

Maristela Duarte Fujimoto Freitas (maristelafujimoto@gmail.com) - Pós-graduação em Engenharia de Processos Químicos e Bioquímicos, Universidade Federal do Rio de Janeiro (EPQB / UFRJ).

Fabio de Almeida Oroski (oroski@eq.ufrj.br) - Pós-graduação em Engenharia de Processos Químicos e Bioquímicos, Universidade Federal do Rio de Janeiro (EPQB / UFRJ).

\section{RESUMO}

Segundo a Food and Agriculture Organization (FAO), cerca de 1/3 de tudo que é produzido no mundo, é perdido ou desperdiçado ao longo dos estágios das cadeias produtivas. Trata-se de um problema de natureza social, econômica e social. Nesse contexto, têm surgido soluções inovadoras que promovem a circularidade na cadeia de alimentos e buscam soluções para as perdas e desperdício de alimentos. Dentre essas, as plataformas digitais que promovem inovações no sistema alimentar em sua transição do modelo linear para o circular. Todavia, o sucesso dessas plataformas depende da superação de múltiplas barreiras. Nesse contexto, este estudo teve como objetivo explorar as principais barreiras à circularidade no combate ao excedente, perda e desperdício de alimentos no cenário brasileiro. Foram elaborados cinco estudos de caso a partir de entrevistas realizadas com os fundadores das plataformas digitais. O estudo identificou que as barreiras apontadas nas entrevistas são de natureza diversa, além das barreiras tecnológicas, e para o caso brasileiro, a ausência de uma política pública específica para o caso do desperdício de alimentos, dificulta o desenvolvimento desses negócios.

Palavras chave: perda e desperdício de alimentos; plataformas digitais; economia circular, modelo de negócio circular. 


\section{INTRODUÇÃO}

Em 2011, a FAO estimou que cerca de 1/3 da produção de alimentos é perdida ou desperdiçada no mundo, e aproximadamente 1,3 bilhão de toneladas de alimentos são perdidas anualmente ao longo da cadeia de suprimentos (FAO, 2013). Mais recentemente, dados indicam que 1,6 bilhão de alimentos são desperdiçados anualmente no mundo (PORPINO, GUSTAVO; LOURENÇO, CARLOS EDUARDO; ARAUJO, CECILIA M LOBO DE; BASTOS, 2018). O termo perda refere-se à diminuição da quantidade ou qualidade dos alimentos originalmente produzidos para consumo humano, e ocorre ao longo da cadeia, desde a colheita até, mas não incluindo, o nível de varejo. Já o termo desperdício, refere-se aos alimentos próprios para consumo humano que são descartados, seja por opção, descuido ou de forma intencional e ocorre no varejo e nos níveis de consumo (FAO, 2018, 2019).

A produção e a logística envolvida na sua comercialização de alimentos demandam uma quantidade expressiva de terra, água, energia e insumos agrícolas (FAO, 2018; PEIXOTO; PINTO, 2016), assim, a perda e desperdício de alimentos (PDA) tornam-se um desperdício desses recursos e consequentemente, uma agressão ao meio ambiente. Em contradição, a insegurança alimentar (aquela em que pessoas não têm acesso regular a alimentos nutritivos e suficientes, mesmo que não sofram com a fome) afeta cerca de 1,25 bilhão de pessoas no mundo, situação agravada pela pandemia do novo coronavírus (BENÍTEZ, 2020). Portanto, é possível afirmar que a PDA é um problema de natureza social, econômica e ambiental, que deve ser enfrentado com urgência por governos, empresas e sociedade civil (CHABOUD; DAVIRON, 2017; FAO, 2018).

Nesse contexto, têm surgido soluções inovadoras que promovem a circularidade na cadeia de alimentos e buscam possíveis soluções para as PDAs (PEIXOTO; PINTO, 2016). Em 2015, na conferência da Organização das Nações Unidas (ONU) entre os 17 Objetivos de Desenvolvimento Sustentável, foi proposto o ODS 12.3, que visa reduzir o desperdício de alimentos em 50\% até o ano de 2030 (BENÍTEZ, 2020). No mesmo ano, a União Europeia (UE) lançou um plano de ação para a economia circular (EC), priorizando ações para quantificação, compartilhamento de boas práticas de mitigação das PDAs e educação dos consumidores (PORPINO, GUSTAVO; LOURENÇO, CARLOS EDUARDO; ARAUJO, CECILIA M LOBO DE; BASTOS, 2018). Percebe-se que a solução desse problema exige o surgimento de inovações que promovam circularidade na cadeia de alimentos e políticas 
públicas que incentivem a implementação desses modelos circulares (HENZ; PORPINO, 2017; OROSKI, 2020).

A EC se baseia na valorização dos recursos e minimização dos resíduos a partir de três pilares (3 R’s): Reduzir, Reutilizar e Reciclar (GHISELLINI; CIALANI; ULGIATI, 2016; LACY; RUTQVIST, 2015). Assim, produtos e materiais continuam circulando nos chamados "loops" pelo tempo que puderem fornecer valor (RANTA; AARIKKA-STENROOS; MÄKINEN, 2018). Porém, a introdução da circularidade no sistema alimentar impõe desafios muito diferentes daqueles observados em materiais e produtos como plásticos, têxteis, eletrônicos e outros (TEIGISEROVA; HAMELIN; THOMSEN, 2020). Por exemplo, os alimentos se diferenciam em termos de perecibilidade e condições de manuseio, distribuição e armazenamento (GARRONE; MELACINI; PEREGO, 2014).

No Brasil e no mundo, têm surgido plataformas digitais de combate à PDA, que promovem inovações no sistema alimentar, na transição do modelo linear para o circular (HARVEY et al., 2020). Os empreendedores que apostam nessa inovação, viram no desperdício uma oportunidade. Tais plataformas promovem a circularidade, conectando elos distintos da cadeia (CIULLI; KOLK; BOE-LILLEGRAVEN, 2020), reintroduzindo excedentes, alimentos fora do padrão comercial ou perto do prazo de validade, para que estes não se transformem em perda ou desperdício (HARVEY et al., 2020; OROSKI, 2020). Porém, essas plataformas digitais precisam lidar com barreiras e desafios de diversas naturezas para a sua implementação (CIULLI; KOLK; BOE-LILLEGRAVEN, 2020; HARVEY et al., 2020; OROSKI, 2020). No Brasil, essas plataformas têm surgido num ambiente pouco propício para essas inovações, onde não existe uma política nacional específica para o combate à perda e o desperdício de alimentos (HENZ; PORPINO, 2017), o que demanda maior atenção para os desafios à sua implementação.

Nesse contexto, uma questão principal aparece: Quais as principais barreiras para a implementação e desenvolvimento das plataformas digitais de combate a PDA no Brasil? Diante disto, o objetivo principal deste artigo é explorar e identificar as principais barreiras para implementação de soluções inovadoras que visam o combate à PDA no Brasil, e fazem desse problema uma oportunidade de negócio. Para isso, este estudo se propõe a estruturar e analisar cinco estudos de caso de plataformas digitais que combatem a PDA no caso brasileiro. 
A exploração de plataformas digitais que combatem a PDA se justifica pois: (1) existe uma lacuna na literatura sobre a exploração de modelos de negócio de iniciativas que promovam a circularidade (GHISELLINI; CIALANI; ULGIATI, 2016; GULDMANN; HUULGAARD, 2020), (2) faz-se necessário compreender como introduzir modelos de negócios circulares no caso dos alimentos, considerando suas especificidades (BORRELLO et al., 2020; LÜDEKE-FREUND; GOLD; BOCKEN, 2019) e (3) contribui no conhecimento sobre as principais barreiras para a implementação de negócios circulares no caso brasileiro, especificamente no campo da PDA. Espera-se, portanto, que os resultados deste estudo contribuam para o enriquecimento e compreensão do tema por inovadores e formuladores de políticas públicas no contexto brasileiro sobre os principais desafios em inovar através de plataformas digitais no combate a PDA.

\section{METODOLOGIA}

Esta pesquisa se baseia na exploração de estudos de casos de plataformas digitais que combatem a PDA no Brasil. Estudo de caso é uma estratégia de pesquisa empírica que permite uma melhor compreensão de um fenômeno contemporâneo dentro de seu contexto de vida real (EISENHARDT, 1989). O presente estudo adota uma abordagem de amostragem propositiva (MACHADO-DA-SILVA, 2003), em que os exemplos foram previamente selecionados de acordo a responder as perguntas propostas. O método de pesquisa está dividido em quatro principais etapas (Figura 1):

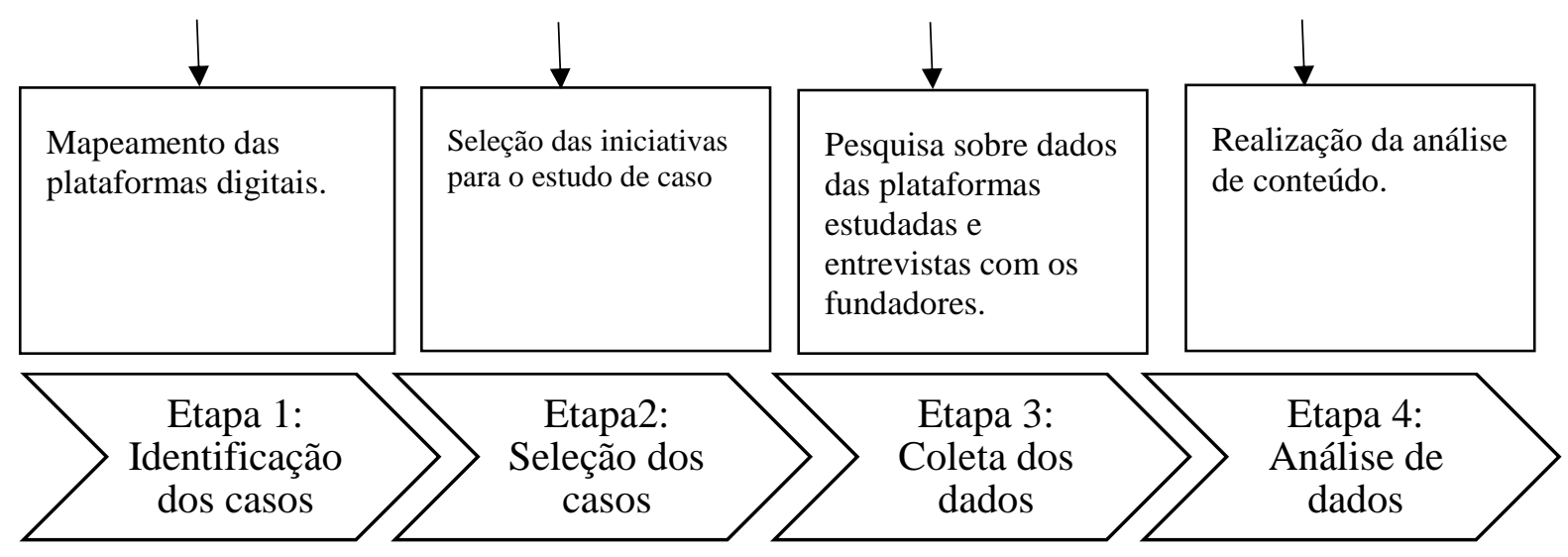


FIGURA 1- Etapas da metodologia para a construção dos estudos de casos

A partir de buscas na internet em websites da imprensa geral e especializada e em relatórios de organizações nacionais e internacionais, levantou-se uma lista de iniciativas circulares que combatem às PDAs no Brasil (Etapa 1). Em seguida, foram estabelecidos dois critérios para seleção das iniciativas que seriam estudadas (Etapa 2): (1) todas as iniciativas deveriam ser oriundas da sociedade civil e, (2) orientadas para a geração de lucro. Depois de selecionadas as iniciativas, os fundadores das empresas foram contactados via redes sociais e e-mail, e os que aceitaram participar do presente estudo (cinco plataformas), foram entrevistados por videoconferência.

Na Etapa 3, realizou-se uma busca por informações básicas sobre cada empresa, e assim, foi possível uma compreensão inicial de cada negócio. Em seguida, foram conduzidas entrevistas com os fundadores das plataformas digitais. As entrevistas foram realizadas entre janeiro e novembro de 2020, e conduzidas pelos autores deste trabalho. Foram realizadas entrevistas semiestruturadas a partir de um questionário previamente elaborado, com duração média de 1 hora.

Por fim, realizou-se uma análise de conteúdo das entrevistas, baseada na proposta de análise da Bardin (1977). Primeiramente, as unidades de codificação (palavras chave referentes ao tema), foram definidas a partir da literatura. Em seguida, realizou-se a transcrição e análise das entrevistas, onde buscou-se por trechos das entrevistas que citavam (de forma direta e/ou indireta) as barreiras definidas nas unidades de codificação. Por fim, e com intuito de cruzar informações e identificar as especificidades para o caso, tem-se a comparação dessas barreiras (identificadas nas entrevistas), com o que a literatura existente diz a respeito das barreiras ao desenvolvimento de iniciativas circulares (BARDIN, 1977).

\section{RESULTADOS E DISCUSSÃO}

A seguir, serão apresentados os resultados obtidos a partir da revisão da literatura e das entrevistas realizadas com as cinco startups selecionadas para o presente estudo. Primeiramente, tem-se na tabela 1, uma breve descrição de cada startup. E posteriormente, a discussão das barreiras encontradas para o caso das plataformas digitais que combatem a PDA no Brasil. 
TABELA 1 - Breve análise das plataformas digitais.

\begin{tabular}{|c|c|c|}
\hline Caso & $\begin{array}{l}\text { Ano de } \\
\text { fundação }\end{array}$ & Breve descrição do negócio \\
\hline $\begin{array}{l}\text { Plataforma } \\
\text { digital A }\end{array}$ & 2019 & $\begin{array}{l}\text { Plataforma (aplicativo) que comercializa excedentes de alimentos } \\
\text { de restaurantes a preços reduzidos para consumidores finais }\end{array}$ \\
\hline $\begin{array}{l}\text { Plataforma } \\
\text { Digital B }\end{array}$ & 2018 & $\begin{array}{l}\text { Plataforma que reúne menus e receitas postadas por parceiros } \\
\text { comerciais (chefs de cozinha, nutricionistas, empresas de } \\
\text { alimentos e consumidores). O usuário acessa a plataforma em } \\
\text { busca dessas receitas. A partir da seleção de uma receita, uma } \\
\text { lista de compras é gerada com apenas os ingredientes necessários, } \\
\text { evitando excesso nas compras e consequente desperdício. }\end{array}$ \\
\hline $\begin{array}{c}\text { Plataforma } \\
\text { Digital C }\end{array}$ & 2017 & $\begin{array}{l}\text { Plataforma que conecta fornecedores de alimentos ao setor de } \\
\text { varejo e ao food service (restaurantes industriais, catering, bares, } \\
\text { ONGs, lanchonetes, hotéis e similares) através da venda de } \\
\text { alimentos fora do padrão e/ou perto do prazo de validade. }\end{array}$ \\
\hline $\begin{array}{l}\text { Plataforma } \\
\text { Digital D }\end{array}$ & 2020 & $\begin{array}{l}\text { Plataforma (aplicativo) que comercializa excedentes de alimentos } \\
\text { de bares, cafeterias, padarias, entre outros, a preços reduzidos. }\end{array}$ \\
\hline $\begin{array}{l}\text { Plataforma } \\
\text { Digital E }\end{array}$ & 2018 & $\begin{array}{c}\text { Plataforma que oferece serviços de estruturação e inteligência dos } \\
\text { processos de doação de alimentos, para que se possa otimizar os } \\
\text { benefícios para o doador e o receptor. }\end{array}$ \\
\hline
\end{tabular}

Fonte: Elaboração própria a partir das entrevistas e sites das plataformas.

Depois da compreensão da atuação de cada startup, foram definidas (a partir da literatura), as barreiras ao desenvolvimento de negócios circulares, indicadas na tabela 2. Com a definição destas barreiras, foi possível a exploração das entrevistas, com intuito de encontrar 
a indicação direta e indireta dessas barreiras, e entender as especificidades para o caso dessas plataformas. Exemplos de trechos das entrevistas que citam de forma direta e indireta as barreiras identificadas a partir da literatura, também estão na tabela 2 .

TABELA 2 - Barreiras citadas nas entrevistas

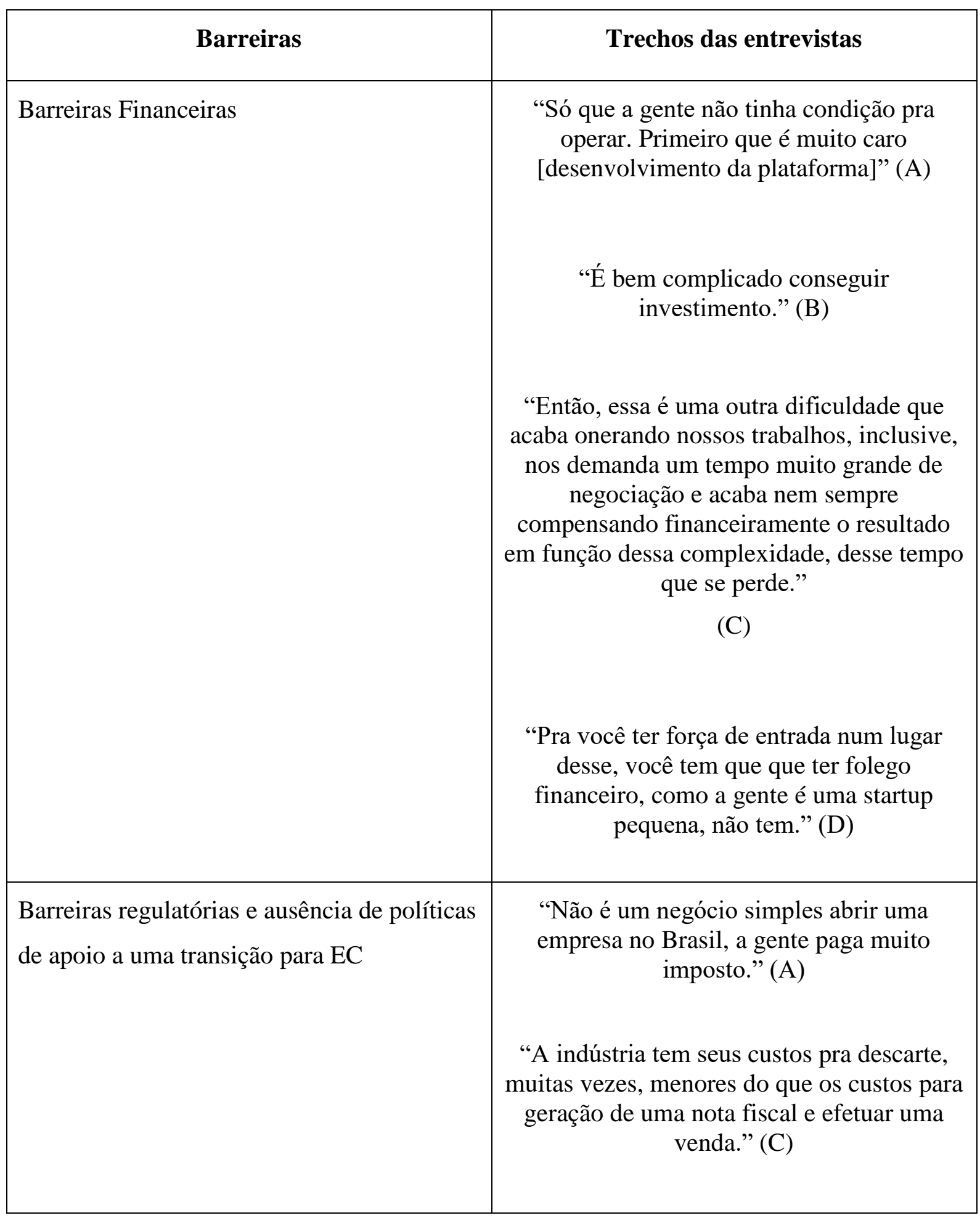




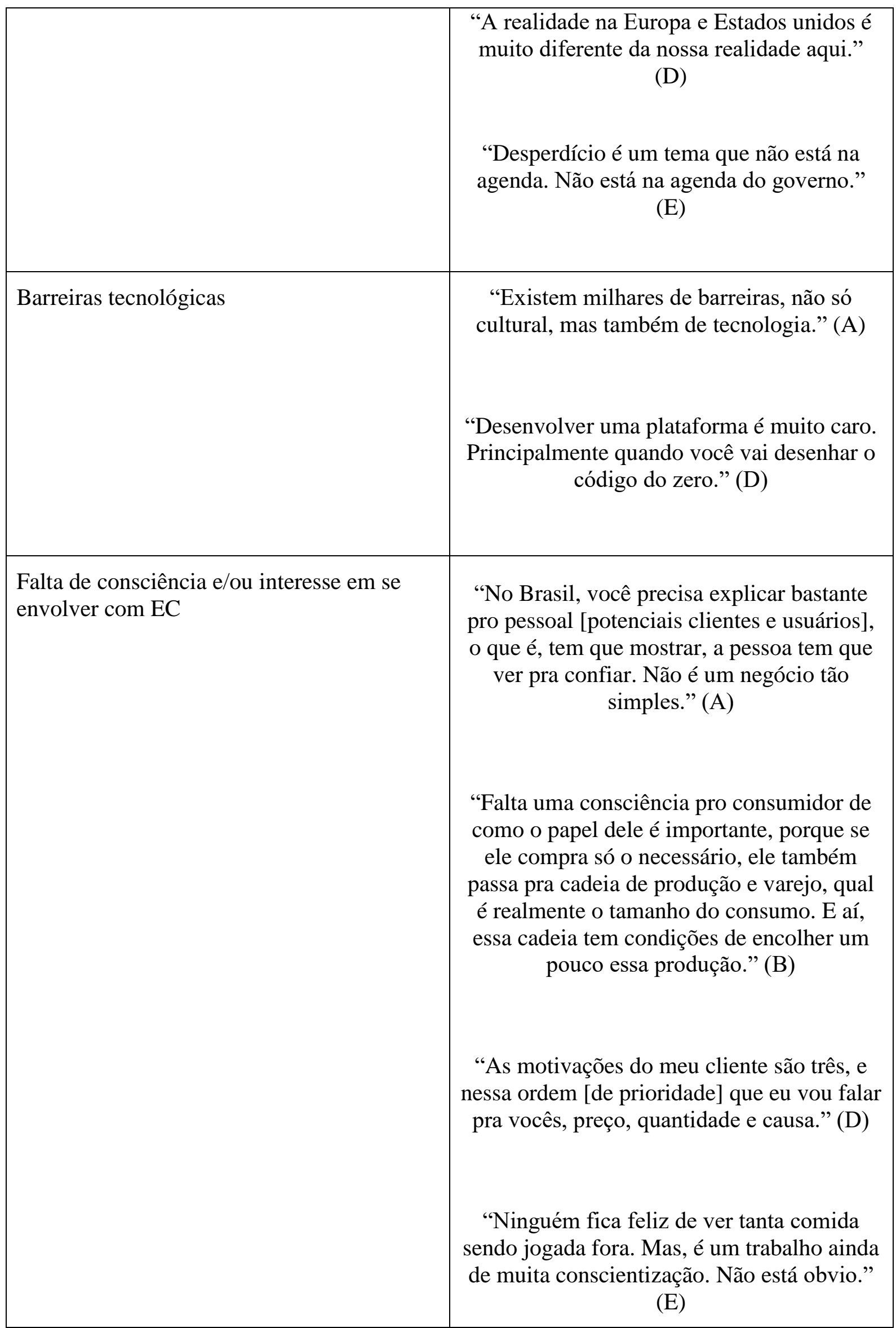




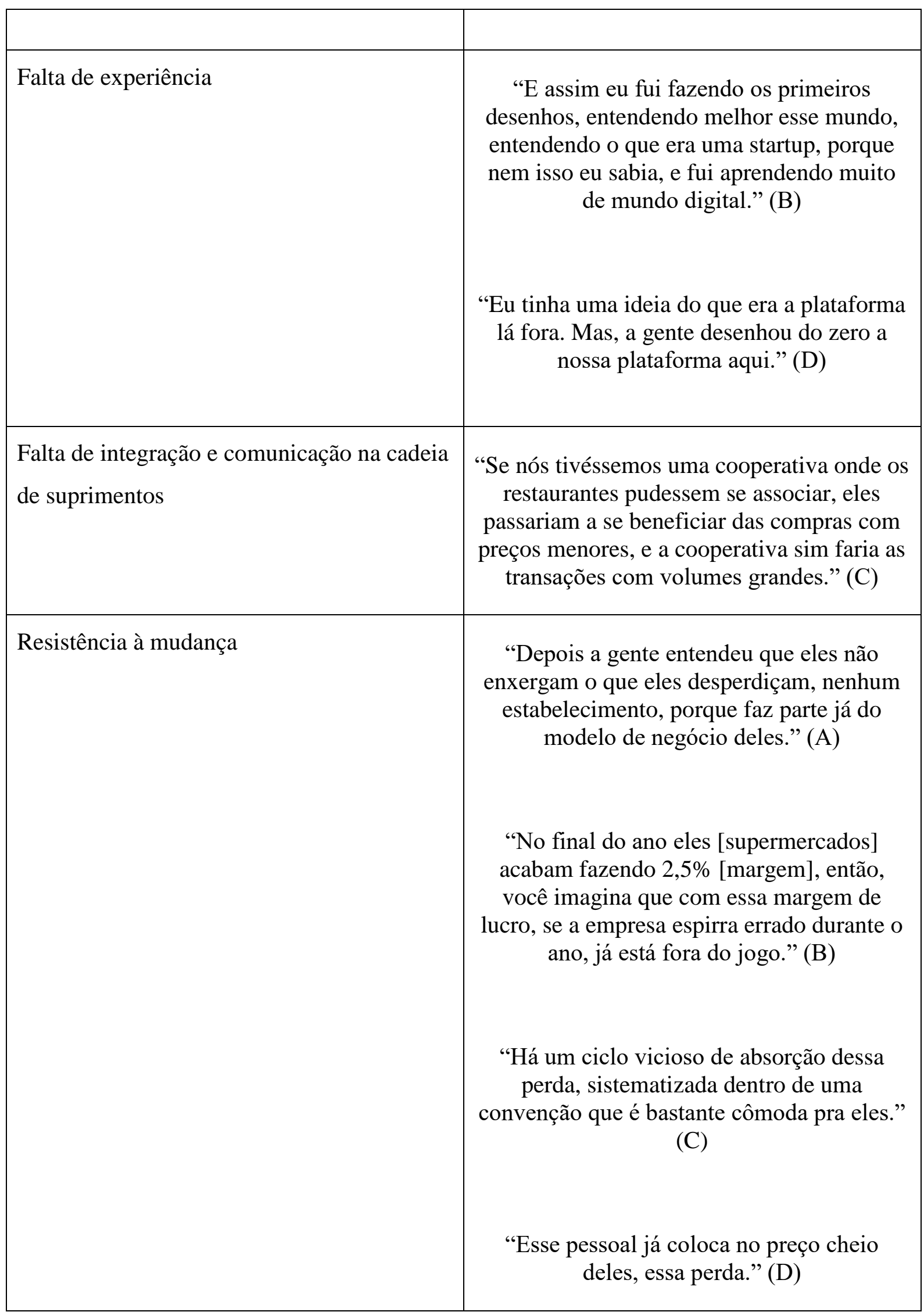




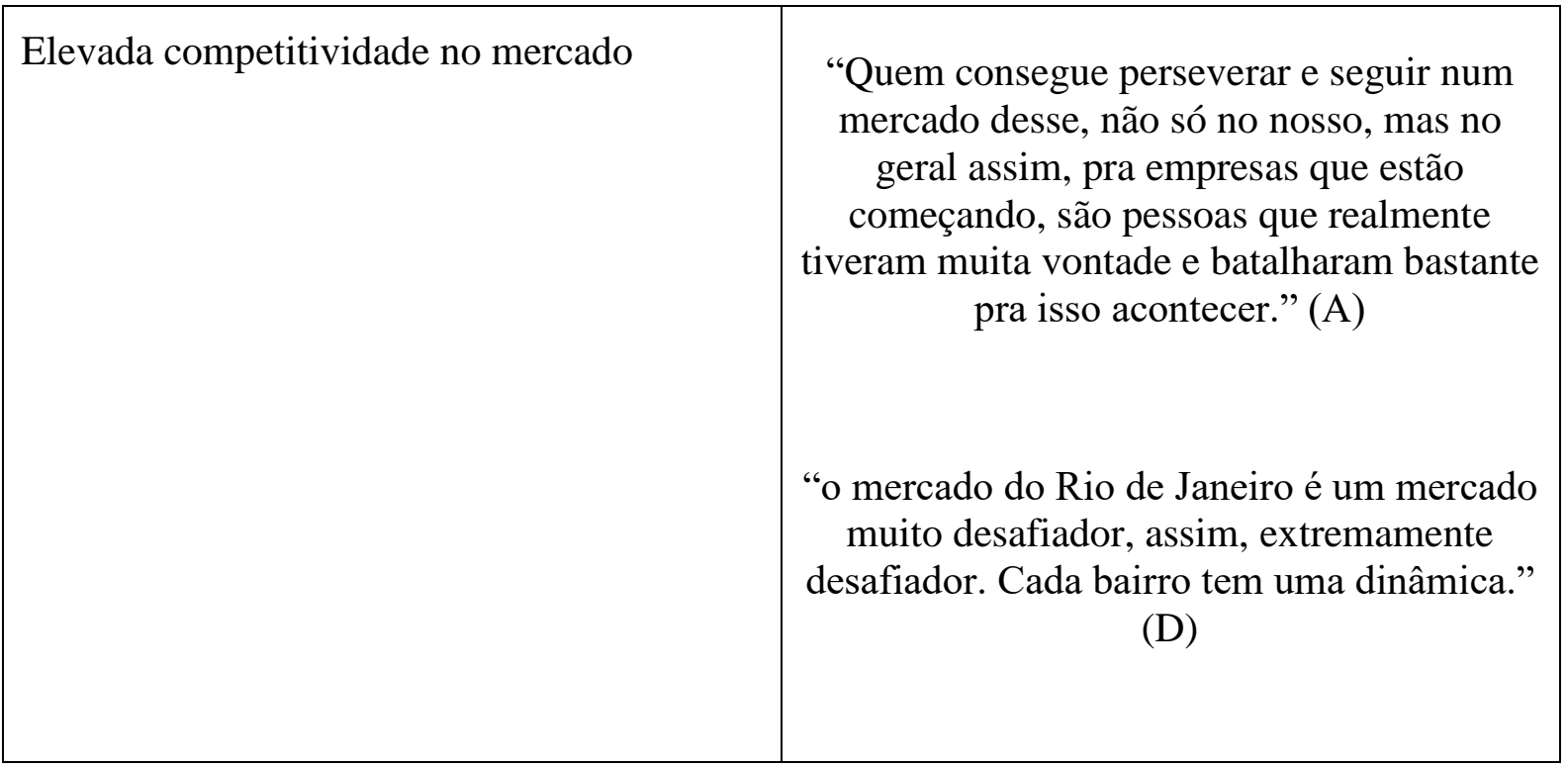

A disponibilidade ou a falta de recursos condicionam a disposição de uma empresa para inovar (GARCÍA-QUEVEDO; JOVÉ-LLOPIS; MARTÍNEZ-ROS, 2020; KIRCHHERR et al., 2018; VERMUNT et al., 2019), por exemplo, "a limitação financeira, limita tecnologicamente, é uma cadeia" (trecho da entrevista com A). Nota-se que, as barreiras impactam umas nas outras e estão relacionadas. Além disso, não existe apenas uma barreira importante, e sim, uma combinação de fatores, que combinados às condições particulares de cada caso, impactam na implementação efetiva da EC (GARCÍA-QUEVEDO; JOVÉLLOPIS; MARTÍNEZ-ROS, 2020). Portanto, tais barreiras não devem ser analisadas de forma isolada.

De acordo com a literatura existente, os produtos circulares tendem a ser mais caros que os convencionais (JAEGER; UPADHYAY, 2020; KIRCHHERR et al., 2018). Se não houver uma regulamentação que os favoreça, fica ainda mais difícil a sua inserção no mercado (GARCÍA-QUEVEDO; JOVÉ-LLOPIS; MARTÍNEZ-ROS, 2020), o que se percebe para o caso brasileiro, de acordo com as entrevistas. Para o caso dos alimentos, o "desperdício é um tema que não está na agenda do governo" (trecho da entrevista com E), o que dificulta o desenvolvimento de negócios que promovem a circularidade na cadeia de alimentos. Assim, nota-se a urgência de políticas públicas estratégicas para o combate ao desperdício de alimentos no Brasil.

A falta de consciência e/ou interesse em se envolver com EC apareceram como importante barreira citada pelas entrevistas. Isso porque, no Brasil, aspectos culturais possuem 
forte impacto no desperdício de alimentos. Preparar refeições em excesso e/ou servir grandes porções de comida e o estoque de grande quantidade de comida são características culturais comuns no Brasil, que podem favorecer o desperdício de alimentos (HENZ; PORPINO, 2017). Nesse sentido, "falta uma consciência pro consumidor de como o papel dele é importante, porque se ele compra só o necessário, ele também passa pra cadeia de produção e varejo, qual é realmente o tamanho do consumo" (trecho da entrevista com B), e assim, a produção e varejo podem encolher a oferta, se adaptando ao consumo real e assim, reduzindo os desperdícios.

A escassez de recursos humanos aliada à inexperiência para o desenvolvimento de atividades de EC constituem um obstáculo para o seu desenvolvimento (GARCÍAQUEVEDO; JOVÉ-LLOPIS; MARTÍNEZ-ROS, 2020). Para o caso de negócios circulares que combatem a PDA no Brasil, essa barreira possui um agravante, dado o desenvolvimento recente desses negócios no país, pois a maioria dessas iniciativas foram implementadas a menos de cinco anos. Os referencias para esses empreendedores são negócios desenvolvidos em outros países. Entretanto, a realidade do Brasil é outra e precisa ser mais bem compreendida: a PDA não está na pauta da política pública e assim, negócios que promovem a circularidade nesse meio, não são favorecidos. As plataformas digitais que atuam no país, "se apropriam de dados internacionais. Mas, não necessariamente tais dados refletem nossa realidade" (trecho da entrevista com A).

A forma como empresas operam ou projetam sua cadeia de abastecimento depende da apreciação dos gerentes. Se houver alguma resistência de gerentes para mudar sua estratégia corporativa, a implementação bem-sucedida da EC pode não acontecer (AGYEMANG et al., 2019). Essa resistência pode estar relacionada à preferência pelo método já estabelecido e receio pelo novo. Além disso, "há um ciclo vicioso de absorção dessa perda, sistematizada dentro de uma convenção que é bastante cômoda pra eles" (trecho da entrevista com C), "e esse valor do desperdício que eles têm, eles embutem no preço de venda" (trecho da entrevista com A). Percebe-se então, que o desperdício já faz parte do modelo de negócio desse setor, e para mudar esse cenário é necessário mudar o comportamento dos atores envolvidos e estabelecer uma legislação específica que impulsione o surgimento de soluções inovadoras que favoreçam essa transição.

O mercado é altamente competitivo e cada vez mais exigente, e essa elevada concorrência no mercado restringe o movimento em direção à EC (JAEGER; UPADHYAY, 
2020). Em muitos casos, a matéria-prima virgem é mais barata e mais fácil de gerenciar em comparação a matéria-prima reciclada (GULDMANN; HUULGAARD, 2020). Os entrevistados afirmaram que, muitas vezes, doar ou desenvolver mercados secundários pode ser mais caro do que o descarte desses produtos. Para o caso das plataformas entrevistadas, percebe-se que a complexidade do mercado é reflexo de outras barreiras já identificadas anteriormente. Por exemplo, a restrição dos clientes ao aceitar a proposta desses negócios, devido a uma desconfiança da qualidade do alimento comercializado, leva a uma maior resistência dos gestores e configura uma importante barreira de mercado. Como consequência, os entrevistados citaram ter sido necessário muito esforço na captação de clientes.

\section{CONCLUSÃO}

A partir das entrevistas, percebe-se que a inovação e a implementação de plataformas digitais para o combate à PDA dependem da superação de barreiras de naturezas diversas, que não se restringem à tecnologia. No caso brasileiro destaca-se o aspecto cultural, como dificuldade relevante, apontada em todas as entrevistas. Hábitos e padrões de consumo precisam ser modificados para que outras barreiras possam ser solucionadas. Nesse aspecto, percebe-se a forte interdependência entre as barreiras encontradas. Essas barreiras indicam que um esforço intenso de relacionamento dos inovadores com os diversos atores das cadeias produtivas envolvidas se faz necessário.

É importante destacar que, além das barreiras identificadas nas entrevistas, existem no caso brasileiro, barreiras de natureza institucional, afinal, a PDA não está na pauta da política pública. Portanto, esses atores promovem a circularidade e a inovação, em um ambiente institucional e regulatório desfavorável, tendo que superar desafios tecnológicos, sociais e culturais. Reafirma-se então, a ideia de que o estabelecimento de uma política e de uma estratégia nacional de combate a PDA favoreceria a superação das barreiras mencionadas e o desenvolvimento de inovações e novos negócios circulares.

\section{REFERÊNCIAS}

AGYEMANG, M. et al. Drivers and barriers to circular economy implementation: An explorative study in Pakistan's automobile industry. Management Decision, v. 57, n. 4, p. 971-994, 2019.

BARDIN, L. Análise de conteúdo. 1977. 
BENÍTEZ, R. O. Perdas e desperdícios de alimentos na América Latina e no Caribe. Disponível em: <http://www.fao.org/americas/noticias/ver/pt/c/239394/>.

BORRELLO, M. et al. Consumers are willing to participate in circular business models: A practice theory perspective to food provisioning. Journal of Cleaner Production, v. 259, 2020.

CHABOUD, G.; DAVIRON, B. Food losses and waste: Navigating the inconsistencies. Global Food Security, v. 12, n. June 2016, p. 1-7, 2017.

CIULli, F.; KOLK, A.; BOE-LILlEGRAVEN, S. Circularity Brokers: Digital Platform Organizations and Waste Recovery in Food Supply Chains. [s.1.] Springer Netherlands, 2020. v. 167

EISENHARDT, K. M. Building Theories from Case Study Research. v. 14, n. 4, p. 532-550, 1989.

FAO. Food wastage footprint. [s.1: s.n.].

FAO. Gender and food loss in sustainable food value chains. [s.l: s.n.].

FAO. The state of food and agriculture. [s.l: s.n.].

GARCÍA-QUEVEDO, J.; JOVÉ-LLOPIS, E.; MARTÍNEZ-ROS, E. Barriers to the circular economy in European small and medium-sized firms. Business Strategy and the Environment, v. 29, n. 6, p. 2450-2464, 2020.

GARRONE, P.; MELACINI, M.; PEREGO, A. Opening the black box of food waste reduction. Food Policy, v. 46, p. 129-139, 2014.

GHISELLINI, P.; CIALANI, C.; ULGIATI, S. A review on circular economy: The expected transition to a balanced interplay of environmental and economic systems. Journal of Cleaner Production, v. 114, p. 11-32, 2016.

GULDMANN, E.; HUULGAARD, R. D. Barriers to circular business model innovation: A multiple-case study. Journal of Cleaner Production, v. 243, p. 118160, 2020.

HARVEY, J. et al. Food sharing, redistribution, and waste reduction via mobile applications: A social network analysis. Industrial Marketing Management, v. 88, n. April 2018, p. 437-448, 2020.

HENZ, G. P.; PORPINO, G. Food losses and waste: how Brazil is facing this global challenge? Horticultura Brasileira, v. 35, n. 4, p. 472-482, 2017.

JAEGER, B.; UPADHYAY, A. Understanding barriers to circular economy: cases from the manufacturing industry. Journal of Enterprise Information Management, v. 33, n. 4, p. 729-745, 2020.

KIRCHHERR, J. et al. Barriers to the Circular Economy: Evidence From the European Union (EU). Ecological Economics, v. 150, n. December 2017, p. 264-272, 2018.

LACY, P.; RUTQVIST, J. Waste to Wealth - the circular economy advantage. [s.l: s.n.].

LÜDEKE-FREUND, F.; GOLD, S.; BOCKEN, N. M. P. A Review and Typology of Circular Economy Business Model Patterns. Journal of Industrial Ecology, v. 23, n. 1, p. 36-61, 2019.

MACHADO-DA-SILVA, C. L. Qualitative research \& evaluation methods. 3. ed. London: Sage, 2003. v. 7

OROSKI, F. DE A. Food Waste Management - Solving the Wicked problem. In: Food Waste Management. [s.l: s.n.]. p. 367-389.

PEIXOTO, M.; PINTO, H. S. Desperdício de alimentos: questões socioambientais, econômicas e regulatórias. p. 1-14, 2016.

PORPINO, GUSTAVO; LOURENÇO, CARLOS EDUARDO; ARAUJO, CECILIA M LOBO DE; BASTOS, A. Intercâmbio Brasil - União Europeia sobre desperdício de alimentos: Relatório final. p. 40, 2018.

RANTA, V.; AARIKKA-STENROOS, L.; MÄKINEN, S. J. Creating value in the circular economy: A structured multiple-case analysis of business models. Journal of Cleaner Production, v. 201, p. 988-1000, 2018 .

TEIGISEROVA, D. A.; HAMELIN, L.; THOMSEN, M. Towards transparent valorization of food surplus, waste and loss: Clarifying definitions, food waste hierarchy, and role in the circular economy. Science of the Total Environment, v. 706, n. January 2020, p. 136033, 2020.

VERMUNT, D. A. et al. Exploring barriers to implementing different circular business models. Journal of 
Cleaner Production, v. 222, p. 891-902, 2019. 